\title{
Migración del uso residencial de la vivienda al alquiler turístico en Sevilla. Impactos en el derecho a vivir en la ciudad
}

\author{
Migration from residential use of housing to tourist rental in Seville. \\ Impacts on the right to live in the city
}

\author{
Hugo Pereira ${ }^{1}$
}

Fecha de recepción: 04-07-2020 - Fecha de aceptación: 11-04-2021

Hábitat y Sociedad (ISSN 2173-125X), n. ${ }^{\circ}$ 14, noviembre de 2021, pp. 119-138.

https://doi.org/10.12795/HabitatySociedad.2021.i14.07

\section{Summary}

The analysis of the impacts on residential housing in the city of Seville by tourist rental has been the main objective that has guided the carrying out of this work. To achieve this the behavior of the rental of housing for tourist purposes, the evolution of the rental cost and the prices of the houses were characterized. The effects of tourist rental experienced by Sevillian residents were also examined. Organized resistance against the impact of intensive tourism in Seville is recent. The Collective Assembly against the Touristization of Seville (CACTUS) began to take its first steps a few years ago. Its members consider that the migration from residential to tourist-type rental not only expels the resident population, but that with the emptying of the neighborhoods, the solidarity networks that have been typical of Sevillian neighborhoods also disappear.

\section{Key words}

Touristization; housing for tourist purposes; residential rental; CACTUS; Seville

\section{Resumen}

El análisis de los impactos en la vivienda residencial de la ciudad de Sevilla por parte del alquiler turístico ha sido el objetivo principal que ha guiado la realización de este trabajo. Para lograrlo se caracterizó el comportamiento del alquiler de viviendas con fines turísticos, la evolución del costo del alquiler y los precios de las viviendas. Se examinaron también los efectos del alquiler turístico experimentados por los residentes sevillanos. La resistencia organizada contra el impacto del turismo intensivo en Sevilla es reciente. El Colectivo Asamblea contra la Turistización de Sevilla (CACTUS) empezó a dar sus primeros pasos muy pocos años atrás. Sus integrantes consideran que la migración del alquiler residencial al de tipo turístico no solo expulsa a la población residente, sino que con el vaciamiento de los barrios desaparecen también las redes de solidaridad que han sido propias de las vecindades sevillanas.

\section{Pallabras clave}

Turistización; Viviendas con fines turísticos; Alquiler residencial; CACTUS; Sevilla

1 Licenciado en Ciencias de la Educación con énfasis en Ciencias Sociales. Especialista y Máster en Metodología de la Investigación Científica. Candidato a Doctor en Ciencias Sociales por la Universidad de Buenos Aires. Investigador del Centro de Estudios Rurales Interdisciplinarios (CERI) y del Consejo Nacional de Ciencia y Tecnología de Paraguay (CONACYT). E-mail: hugopereirac@gmail. com. ORCID: https://orcid.org/0000-0003-4226-4613. 


\section{Introducción²}

El Colectivo-Asamblea contra la Turistización de Sevilla (CACTUS), surgido a partir de un encuentro de residentes sevillanos en noviembre del año 2017 como un espacio de articulación ciudadana de denuncia y lucha en contra de los impactos del turismo intensivo, ingresó en el 2020 a una etapa de reflexión en el marco de la paralización de actividades producida por las medidas sanitarias tomadas para hacer frente a la pandemia de la COVID-19. Ha hecho un llamado a los interesados e interesadas a aportar su experiencia sobre la manera en que la turistización les afectó en los últimos años y su abrupta interrupción como consecuencia de la crisis generada por el Coronavirus. También ha invitado a pensar en propuestas que apunten al cambio de un modelo económico que tiene como pilar al turismo. La expulsión de los inquilinos de los barrios turistizados es la principal preocupación del CACTUS, la que se resume en el título de su campaña: "Sobrevivienda al turismo".

El turismo se convirtió en una de las actividades económicas de mayor expansión a escala global (Font Garolera, Colom Oliva y ImbertBouchard Ribera, 2018). Aproximadamente 4000000 de los turistas que arribaron a Andalucía en el 2017 visitaron la provincia de Sevilla, lo que representó ese año el 13\% del flujo turístico andaluz, posicionándose entonces en el cuarto lugar entre todas las provincias. La ciudad del sur español y europeo, con alrededor de 700000 habitantes, recibió en el 2017 a casi 3000000 de turistas, una cifra 4 veces superior a su población. Como se puede ver en el Cuadro 1, algo similar ocurrió con Andalucía. Hasta allí llegó un número de excursionistas más de 3 veces superior al de sus habitantes.

Cuadro 1: Relación de número de turistas y habitantes de Andalucía y la ciudad de Sevilla. Año 2017. Fuente: Instituto de Estadística y Cartografía de Andalucía/ Padrón municipal de habitantes del Ayuntamiento de Sevilla/ Centro de Datos Turísticos 2017. Elaboración propia.
2 El presente artículo es producto de una estancia corta de investigación en la ciudad de Sevilla, realizada a invitación del Grupo de Investigación de Geografía del Desarrollo Rural y Urbano, adscrito a la Universidad de Sevilla, con la financiación del Consejo Nacional de Ciencia y Tecnología de Paraguay (CONACYT), en el marco del Programa de Vinculación de Científicos y Tecnólogos, convocatoria 2018.

\begin{tabular}{|l|c|c|c|}
\hline Área geográfica & Turistas & Población & Relación \\
\hline $\begin{array}{l}\text { Comunidad } \\
\text { autónoma de } \\
\text { Andalucía }\end{array}$ & 29731276 & 8379820 & 3,5 \\
\hline Ciudad de Sevilla & 2907754 & 698690 & 4,2 \\
\hline
\end{tabular}

El alojamiento de turistas es absorbido en la provincia de Sevilla por los hoteles y otros sitios tradicionales de hospedaje, pero también por las viviendas con fines turísticos (VFT), de cuya magnitud numérica en territorio andaluz se empezó a tener información más precisa de manera reciente. En febrero del año 2016 la Junta de Andalucía emitió un decreto con el objeto de regular las viviendas que ofertan el servicio de alojamiento turístico, de tal manera a que las mismas cuenten con un mínimo de calidad y seguridad para los usuarios (Decreto 28/2016). El decreto define a una vivienda con fines turísticos como aquella ubicada en inmuebles situados en suelo de uso residencial "donde se vaya a ofrecer mediante precio el servicio de alojamiento en el ámbito de la Comunidad Autónoma de Andalucía, de forma habitual y con fines turísticos" (Decreto 28/2016, Art. 3.1).

El documento oficial estableció la obligatoriedad de inscripción de una vivienda con esos fines en el Registro de Turismo de Andalucía (Decreto 28/2016, Art. 9), indicando que se considerará clandestina, y por ende una infracción grave, la prestación del servicio de hospedaje turístico si el titular de la vivienda no realizar la correspondiente declaración e inscripción de esta en el registro oficial (Decreto 28/2016, 
Art. 11). Desde entonces se cuenta con datos estadísticos oficiales de dicha categoría de albergue turístico en Andalucía. A partir de mediados del año 2017 se encuentran referencias periodísticas sobre el excesivo peso que iba ganando el sector, el incremento turístico y la consecuente expulsión de vecinos y vecinas de sus viviendas (Jover, Berranquero, Barrero y Jiménez, 2018), las que se fueron transformando en alojamientos turísticos según confirman los testimonios de residentes desplazados (Barrero Rescalvo y Jover Baéz, 2021).

Los efectos de la sustitución del uso residencial de larga duración de las viviendas por parte de los arrendadores que las destinan al alquiler exclusivo a turistas, alentada por las plataformas de internet, se observan en estudios que abordan la temática como el realizado en el centro histórico de Palma, capital de la comunidad autónoma de las Islas Baleares, España, donde se ha verificado una clara correlación entre las viviendas para uso turístico ofertadas en los portales especializados de internet y las desposesiones de inquilinos (Vives-Miró y Rullan, 2017).

La realidad de las ciudades españolas y de otras de Europa, donde ocurren fenómenos similares, según algunos tiene una evidente relación con políticas turísticas neoliberales que se han impuesto en las ciudades globales desde finales del siglo pasado (Milano, 2018). Las ciudades neoliberales se volvieron predominantes en el mundo (Rodríguez, Delvalle y Ostuni, 2013). Sus políticas públicas están basadas en planificaciones que favorecen las grandes intervenciones urbanas que refuerzan procesos de segregación (Díaz Orueta y Lourés Seoane, 2013; Pereira, 2018). La planificación urbanística puesta al servicio del mercado (Inzulza-Contardo y Díaz Parra, 2016) ha adaptado el espacio público de la ciudad a estándares que generan un ecosistema de consumo que segrega a la población local (Berraquero Díaz, 2016).

Sevilla, la capital de la provincia del mismo nombre y de la comunidad autónoma de Andalucía, es una ciudad con alrededor de 3000 años de historia (Campos Carrasco, 1986, citado en Jover Báez, 2017), plasmada en sus monumentos y edificios que atestiguan la presencia de varias culturas. A lo largo de los milenios, los diferentes grupos humanos que la habitaron dejaron una marca imborrable en su entorno urbano, el que se constituye en uno de los principales atractivos para los viajeros. En efecto, en el 2018 Sevilla fue considerada el mejor destino turístico urbano a nivel mundial (Jover Báez y Berraquero Díaz, 2020).

El flujo turístico en Sevilla ha pasado por determinados períodos en los que se ha podido comprobar el fortalecimiento del sector. En la etapa comprendida entre los años 2004 al 2007, la afluencia de visitantes experimentó un incremento anual que no se había conocido desde el año 1992. El factor clave de esa etapa fue la llegada de nuevas conexiones aéreas de compañías de bajo costo. En el período 2007-2009 la crisis económica registrada en España y en el mundo generó el mayor descenso de pernoctaciones de las décadas anteriores, pero no produjo el cierre de ningún establecimiento hotelero, lo que es interpretado como una muestra de solidez que adquirió el turismo. Entre los años 2010 al 2015 se verificó un acelerado crecimiento de la actividad turística con picos históricos de pernoctaciones y ocupación hotelera, además de la incorporación de nuevas tendencias turísticas (Villar Lama y Fernández Tabales, 2017).

El crecimiento del mencionado movimiento ha generado transformaciones como la incorporación de áreas tradicionalmente residenciales a circuitos turísticos, lo que se ha traducido en el aumento de viviendas turísticas y la reducción de la oferta de alquileres para uso re- 
sidencial (Jover y Díaz-Parra, 2019). Además, la especialización turística de Sevilla ha incidido en el desplazamiento del comercio local y la expansión de establecimientos de marcas multinacionales como cadenas de supermercados o tiendas de souvenirs cuyos consumidores meta son los visitantes (Jover, 2019). Al inicio de su campaña "Sobrevivienda al turismo", el CACTUS hizo un llamamiento a la autoorganización de toda la vecindad para luchar por el derecho de los residentes sevillanos a permanecer en sus barrios. Es que en Sevilla el acelerado aumento del alquiler turístico ha repercutido en el aumento del precio de la vivienda enajenada y arrendada (Jover Báez y Berraquero Díaz, 2020). Este artículo apunta a dar una mirada a los impactos del alquiler turístico en la vivienda residencial entre los años 2015 al 2020 en la ciudad de Sevilla a partir del análisis de datos estadísticos disponibles y los testimonios grabados a residentes locales.

\section{Fundamentación teórica}

Internet ha posibilitado la irrupción de nuevos intermediarios que ponen en contacto directo a los turistas con los residentes locales (Richards, 2016). Airbnb es un ejemplo de ello. Fundada en el año 2008 a partir de la experiencia de tres estudiantes de San Francisco, Estados Unidos, quienes pusieron tres colchones en el piso y los alquilaron por internet a los visitantes que no querían pagar los altos precios de los hoteles de la ciudad (Yrigoy, 2017). Tenía registrado en 2019 en su plataforma a más de 3000000 alojamientos en más de 190 países (Santucci de Oliveira, Eger Bauer, Tomelin y Lisboa Sohn, 2019).

Aunque a la promoción de servicios y conexión directa entre consumidores y prestadores de servicios mediante las plataformas online se considera un modelo de economía colaborativa o compartida, en realidad se trata, en algunos casos como el de la oferta de viviendas turísticas, de modelos de negocios que nada tienen de colaborativo (Rodríguez-Antón, Alonso-Almeida, Rubio-Andrada y Celemín Pedroche, 2016), tal como lo demuestran algunas investigaciones que constataron que la mayor parte de las viviendas de usos turísticos corresponden a propietarios que concentran en su poder muchas casas y que por lo tanto gestionan múltiples ofertas en las plataformas virtuales, con lo que es una mínima parte de la población local la que comparte sus habitaciones o parte de la vivienda con los turistas (Peñarrubia Zaragoza, Simancas Cruz, Temes Cordovez, Moya Fuero y García Amaya, 2016; Gil y Sequera, 2018).

Las nuevas herramientas de las tecnologías de la información y la comunicación, asociadas a dinámicas de rehabilitación urbana, producto de políticas públicas orientadas a favorecer la inversión inmobiliaria, han generado las condiciones para la llegada de numerosos turistas a las ciudades, lo que ha desembocado en la sustitución de actividades comerciales y servicios locales, así como la expulsión directa o indirecta de los residentes de determinadas áreas urbanas (BarataSalgueiro, 2017). Las actividades productivas de las ciudades que ahora tienen importante flujo de visitantes son reemplazadas por aquellas vinculadas al sector turístico-inmobiliario, produciéndose transformaciones en los barrios turísticos que terminan en procesos de gentrificación (Murray Mas, 2014), la puesta en valor de sectores urbanos cuya población es sustituida por un grupo social de estratificación social superior (Díaz Parra, 2011). 
Se genera así lo que Kevin Gotham (2005) denomina "gentrificación turística", la transformación de un barrio de clase media en un enclave relativamente rico y exclusivo en el que proliferan lugares de entretenimiento corporativo y turismo, incrementándose de esa forma la importancia del consumo en el espacio residencial y produciendo el aumento del valor de las propiedades y los alquileres con el consecuente desplazamiento de personas de bajos ingresos. La elitización del territorio, el encarecimiento de la vivienda y la exclusión social a su acceso son consecuencias del proceso de turistización (Blázquez Salom y Murray Mas, 2010). Gentrificación y turismo intensivo comparten así un patrón común: la mercantilización del espacio (Díaz Parra y Jover, 2021).

La reducción del mercado de alquileres de viviendas de larga duración para residentes, de base mensual, en favor de arrendamientos diarios de pisos para turistas es, por lo tanto, una de las principales manifestaciones de la gentrificación turística, lo que dificulta el acceso de viviendas para la población local que no vaya al mercado de compraventa o herede una casa (Yrigoy, 2017), lo que se constituye en uno de los serios costos del éxito turístico (Benach Rovira, 2016). En efecto, los resultados del turismo presentados de manera positiva se contraponen con los impactos negativos generados por dicho sector económico (Cabrerizo, Sequera y Bachiller, 2016). El crecimiento de la afluencia turística es un factor potencial que priva del derecho a la ciudad a los residentes locales (Díaz Parra y Jover, 2021).

\section{Aspectos metodológicos}

Para el logro del objetivo principal de la investigación, el análisis de los impactos en la vivienda residencial y las experiencias de resistencias ciudadanas a la turistización, fueron capturados datos oficiales de dos fuentes principales: la Junta de Andalucía y el Ayuntamiento de Sevilla, que posibilitaron tener una comprensión de la evolución del comportamiento del alquiler de viviendas con fines turísticos entre los años 2015 al 2020.

La información oficial fue contrastada con la proveniente de las plataformas virtuales a través de las cuales se promocionan las viviendas turísticas. A sus datos se llegó mediante dos emprendimientos colaborativos dedicados a realizar relevamientos independientes sobre el número de anuncios de alquileres turísticos y otras variables derivadas de dichos anuncios. Se trata del proyecto DataHippo, el cual tiene entre sus objetivos recoger datos de anuncios de apartamentos de todo el mundo en diferentes plataformas como Airbnb, HomeAway y otros, y ofrecerlos de manera abierta, accesible y gratuita a la comunidad. Además, se recurrieron a las cifras generadas por Inside Airbnb, un emprendimiento similar que permite a sus usuarios explorar cómo impactan en las ciudades del mundo los anuncios de alquileres de viviendas con fines turísticos realizados en la plataforma Airbnb. Los análisis anteriores fueron complementados con el estudio de las cifras ofrecidas por el portal inmobiliario español Idealista y entrevistas en profundidad a investigadores locales, activistas de organizaciones sociales, vecinos y artistas comprometidos con las causas sociales. 


\section{Resultados}

\section{Caracterización del comportamiento del alquiler de viviendas con fines turísticos en la ciudad de Sevilla}

Datos del Ayuntamiento de Sevilla indican que en el año 2015 existían en el municipio 116 viviendas con fines turísticos, las que subieron a aproximadamente 1400 unidades en el año 2016, 12 veces más (Cuadro 2). La mayor parte de las casas que ofrecían hospedaje a los turistas se encontraban esos años en la capital de la provincia del mismo nombre. Una proporción mínima se distribuía en los otros municipios. Si bien recién desde el 2016 se empezó a registrar en toda Andalucía esta categoría, en virtud de lo establecido en el decreto 28/2016, en el Anuario Estadístico de Sevilla del año 2015 ya se encontraba la cifra de esta categoría de alojamiento.

Cuadro 2: Número de viviendas turísticas de la provincia y municipio de Sevilla. Años 2015 y 2016 . Fuente: Ayuntamiento de Sevilla 2015, p. 349/ Ayuntamiento de Sevilla 2016 , p. 383. Elaboración propia.

Figura 1: Número de viviendas con fines turísticos en la provincia de Sevilla. Años 2016 al 2020. ${ }^{3}$ Fuente: Empresa Pública para la Gestión del Turismo y del Deporte de Andalucía/ Junta de Andalucía. Elaboración propia.

\begin{tabular}{|c|c|c|c|}
\hline Años & $\begin{array}{l}\text { Municipios de } \\
\text { Sevilla }\end{array}$ & $\begin{array}{l}\text { Resto de } \\
\text { provincia }\end{array}$ & $\begin{array}{l}\text { Total provincia } \\
\text { de Sevilla }\end{array}$ \\
\hline 2015 & 116 & 7 & 123 \\
\hline 2016 & 1387 & 36 & 1423 \\
\hline
\end{tabular}

El número de viviendas con fines turísticos se triplicó entre el 2016 y el 2018 en la provincia de Sevilla. La Figura 1 muestra que, de casi 1400 viviendas en el año 2016, se pasó a más de 4000 en el 2018. En el 2017 se sumaron más de 1200 alojamientos de este tipo a los registrados en el 2016, experimentándose así un incremento de casi un 90\%. Entre el 2017 y el 2018, con más de 1500 viviendas turísticas adicionales, el crecimiento fue de casi el 60\% según datos del registro oficial. En el 2019 se superó el número de 5000 unidades, llegando a más de 5500 a febrero del año 2020. En concreto, entre el 2016 y el 2020, la cifra de este tipo de alojamiento se cuadruplicó.

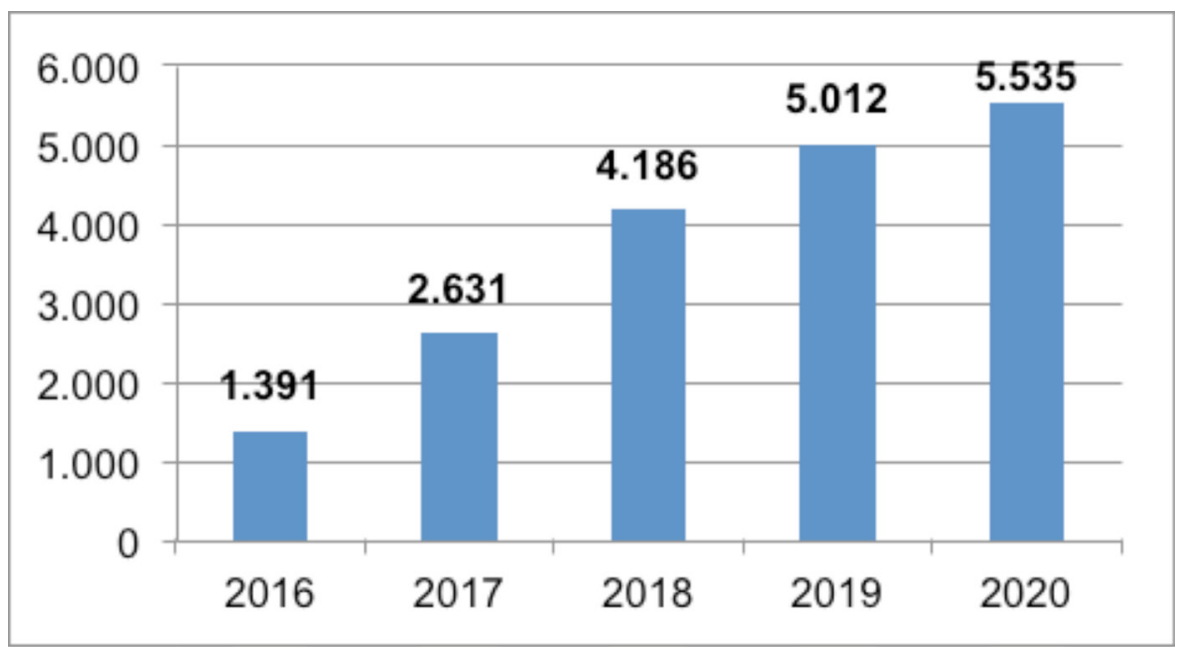

De la misma manera el número de plazas se triplicó entre los años 2016 y 2018, pasando de casi 6600 en el 2016 a más de 20000 unidades en el 2018. El mayor crecimiento proporcional se produjo igualmente entre el 2016 y el 2017, casi un $91 \%$. Mientras tanto, entre el 2017 y el 2018, con más de 7500 plazas adicionales, el incremen-

3 Los datos del 2020 corresponden a los registrados al mes de febrero de ese año. 
to registrado fue de un $60 \%$. En el 2019 se llegó aproximadamente a 24000 y en febrero del 2020 a casi 26600. En 5 años el número de plazas de viviendas turísticas creció 4 veces más, tal como puede constatarse en la Figura 2.

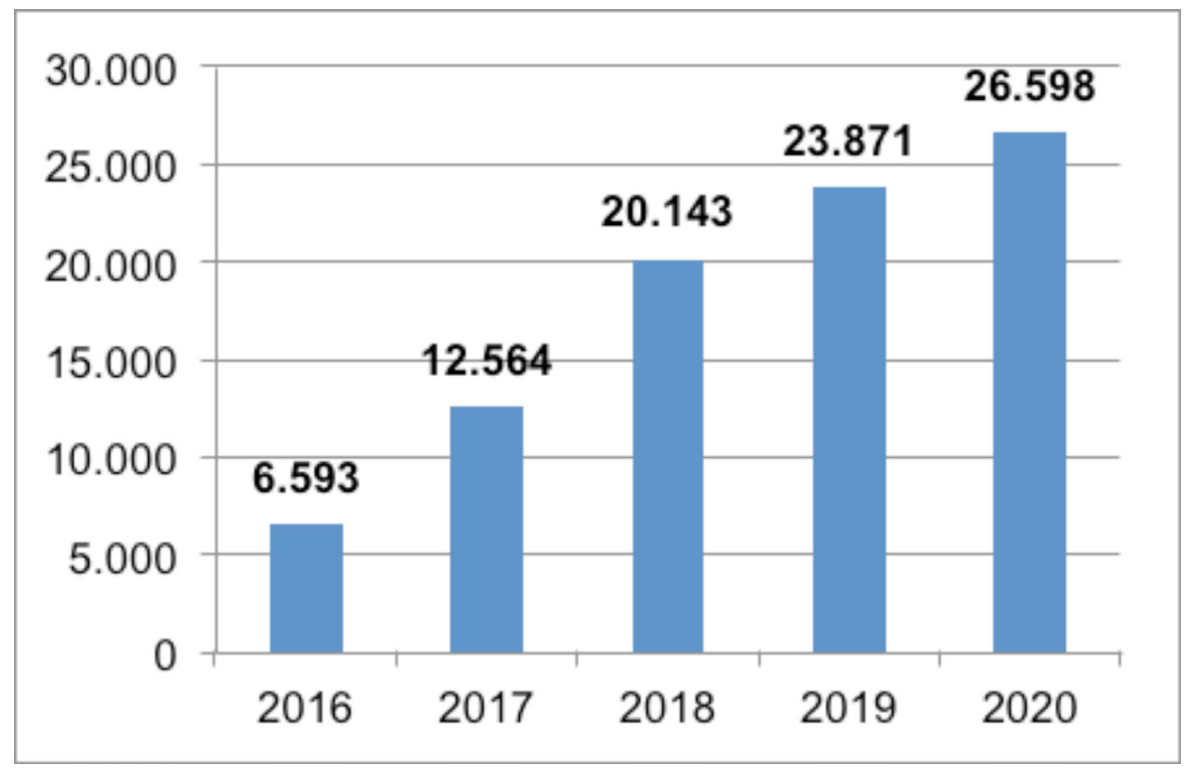

En la Figura 3 se ve que las ofertas de plazas de viviendas con fines turísticos saltaron de un 13,4\%, en el 2016, al 32,4\% en el 2018 en la cuota de participación entre los diferentes tipos de alojamientos turísticos. Por su parte las ofertas de las plazas hoteleras, mayoritarias en el 2016, descendieron de casi un 53\% ese año a un 40\% en el 2018.

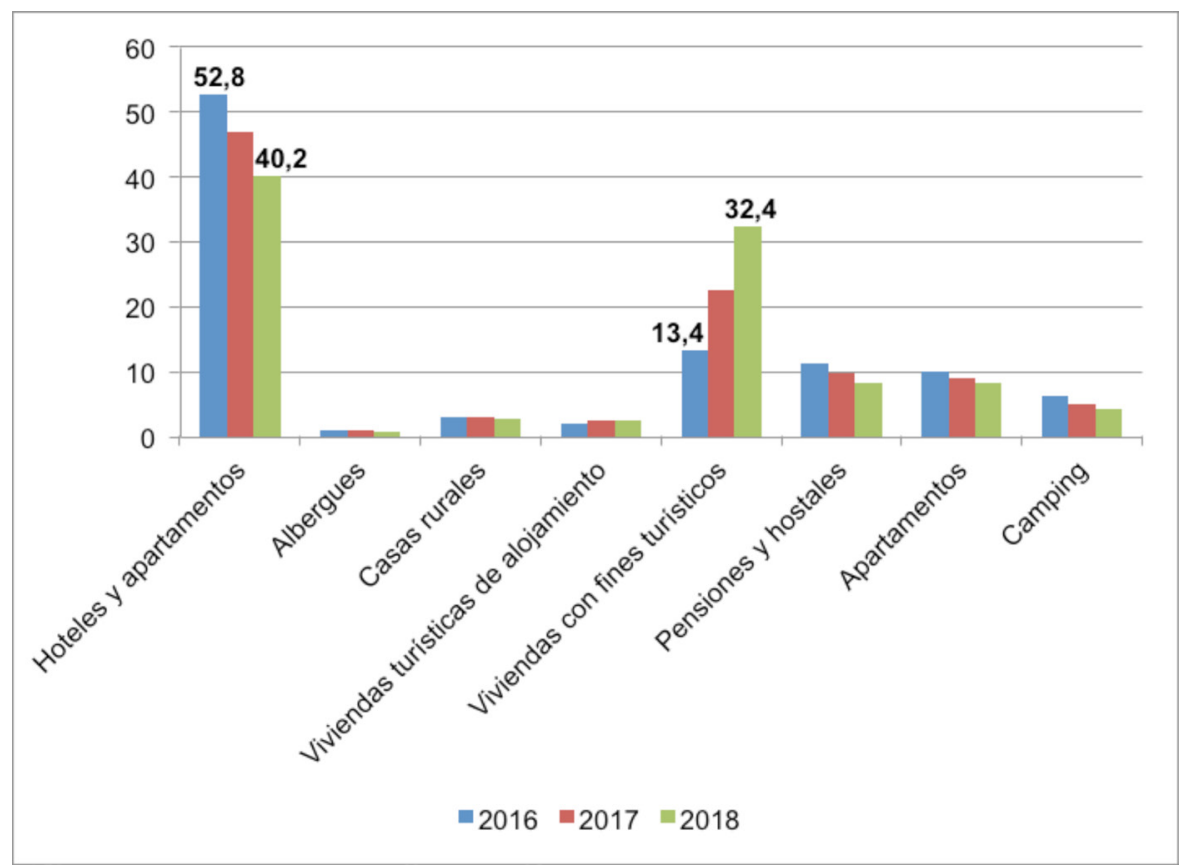

Si bien el número de viviendas con fines turísticos registradas oficialmente ha crecido de manera importante desde el 2015 al 2020, tal como vimos, la cantidad de alojamientos de ese tipo, anunciados en las plataformas virtuales, es mucho mayor. Solo en los 11 distritos de la ciudad de Sevilla, a octubre del 2018, existían más de 7400 anuncios de alquileres de viviendas turísticas en la página web de la compañía Airbnb,
Figura 2: Número de plazas de viviendas con fines turísticos en la provincia de Sevilla. Años 2016 al 2020. ${ }^{4}$ Fuente: Empresa Pública para la Gestión del Turismo y del Deporte de Andalucía/ Junta de Andalucía. Elaboración propia.

Figura 3: Cuota de participación de las diferentes tipologías de alojamiento turístico en la provincia de Sevilla. Años 2016 al 2018 . Fuente: Empresa Pública para la Gestión del Turismo y del Deporte de Andalucía. Elaboración propia.
4 Los datos del año 2020 corresponden a los registrados al mes de febrero de ese año. 
$86 \%$ concentrados en 4 distritos, casi 6400 . El Casco Antiguo y Triana reunían más de las tres cuartas partes de los anuncios. El 24\% restante se distribuía entre los otros 9 distritos.

En los últimos años, muy pocos años, se ha generado el problema, hay un sobre-turismo, hay un exceso de oferta, hay exceso de un nuevo fenómeno, especialmente concentrado en una parte de la ciudad, no en toda la ciudad [...] el centro histórico, el Casco Antiguo y Triana, los barrios históricos, son los que concentran el $85 \%$ a $90 \%$ de la oferta (J. Jover, comunicación personal, 23 de julio de 2018).

Al sumar a los de Airbnb los anuncios de las otras plataformas virtuales como Homeaway, Houset y Onlyap, en la ciudad de Sevilla habrían existido, a octubre del 2018, más de 10000 viviendas con fines turísticos. Más de 7400, casi el 70\%, se encontraban concentradas en el Casco Antiguo como se muestra en el Cuadro 3. Debe considerarse sin embargo que los alojamientos pueden estar anunciados en más de una plataforma. La mayor parte de los anuncios corresponden a Airbnb.

\begin{tabular}{|c|c|c|c|c|c|c|c|c|c|c|c|}
\hline \multirow{2}{*}{ N. ${ }^{\circ}$} & \multirow{2}{*}{ Distritos } & \multicolumn{2}{|c|}{ Airbnb } & \multicolumn{2}{|c|}{ Homeaway } & \multicolumn{2}{|c|}{ Houset } & \multicolumn{2}{|c|}{ Onlyap } & \multicolumn{2}{|c|}{ Total } \\
\hline & & Abs & $\%$ & Abs & $\%$ & Abs & $\%$ & Abs & $\%$ & Abs & $\%$ \\
\hline 1 & Bella Vista-La Palmera & 140 & 1,9 & 17 & 0,8 & 4 & 0,5 & 2 & 0,7 & 163 & 1,5 \\
\hline 2 & Casto Antiguo & 4840 & 65,2 & 1694 & 79,5 & 658 & 79,6 & 245 & 83,6 & 7437 & 69,7 \\
\hline 3 & Cerro-Amate & 96 & 1,3 & 11 & 0,5 & 5 & 0,6 & 3 & 1 & 115 & 1,1 \\
\hline 4 & Este-Alcosa-Torreblanca & 96 & 1,3 & 13 & 0,6 & 1 & 0,1 & 4 & 1,4 & 114 & 1,1 \\
\hline 5 & Los Remedios & 179 & 2,4 & 23 & 1,1 & 5 & 0,6 & 1 & 0,3 & 208 & 1,9 \\
\hline 6 & Macarena & 313 & 4,2 & 42 & 2 & 14 & 1,7 & 6 & 2 & 375 & 3,5 \\
\hline 7 & Nervión & 424 & 5,7 & 106 & 5 & 36 & 4,4 & 11 & 3,8 & 577 & 5,4 \\
\hline 8 & Norte & 95 & 1,3 & 9 & 0,4 & 1 & 0,1 & 0 & 0 & 105 & 1 \\
\hline 9 & San Pablo-Santa Justa & 216 & 2,9 & 21 & 1 & 6 & 0,7 & 1 & 0,3 & 244 & 2,3 \\
\hline 10 & Sur & 210 & 2,8 & 20 & 0,9 & 12 & 1,5 & 4 & 1,4 & 246 & 2,3 \\
\hline 11 & Triana & 815 & 11 & 174 & 8,2 & 85 & 10,3 & 16 & 5,5 & 1090 & 10,2 \\
\hline \multicolumn{2}{|c|}{ Total } & 7424 & 100 & 2130 & 100 & 827 & 100 & 293 & 100 & 10674 & 100 \\
\hline
\end{tabular}

Cuadro 3: Número de anuncios de viviendas con fines turísticos de distritos de la ciudad de Sevilla por plataformas online. Octubre, 2018. Fuente: DataHippo, consultado el 20 de mayo de 2019.
Pese a que ha crecido la oferta de alquileres de viviendas con fines turísticos, el número de oferentes no es equivalente. La mayor parte de las casas de alojamiento de turistas son promocionadas en las plataformas de internet por propietarios de muchos inmuebles. Datos de Inside Airbnb reproducidos en la Figura 4 muestran que el 68\% de los anuncios de viviendas con fines turísticos de la ciudad de Sevilla en la plataforma Airbnb son anuncios múltiples, es decir muchos de ellos son realizados por los mismos propietarios o gestores de alquiler.

En la ciudad Sevilla, a setiembre del 2019, 20 anfitriones anunciaban 664 ofertas de alquiler de viviendas turísticas en Airbnb, el 12\% del total de anuncios de usuarios de la capital andaluza en la plataforma virtual, registrados por Inside Airbnb. El anfitrión con mayor cantidad de ofertas tenía 57 anuncios, mientras que el de menor número de ofertas, 23. Debe aclararse que no es posible deducir con los datos disponibles si los anfitriones son propietarios o en realidad son gestores 


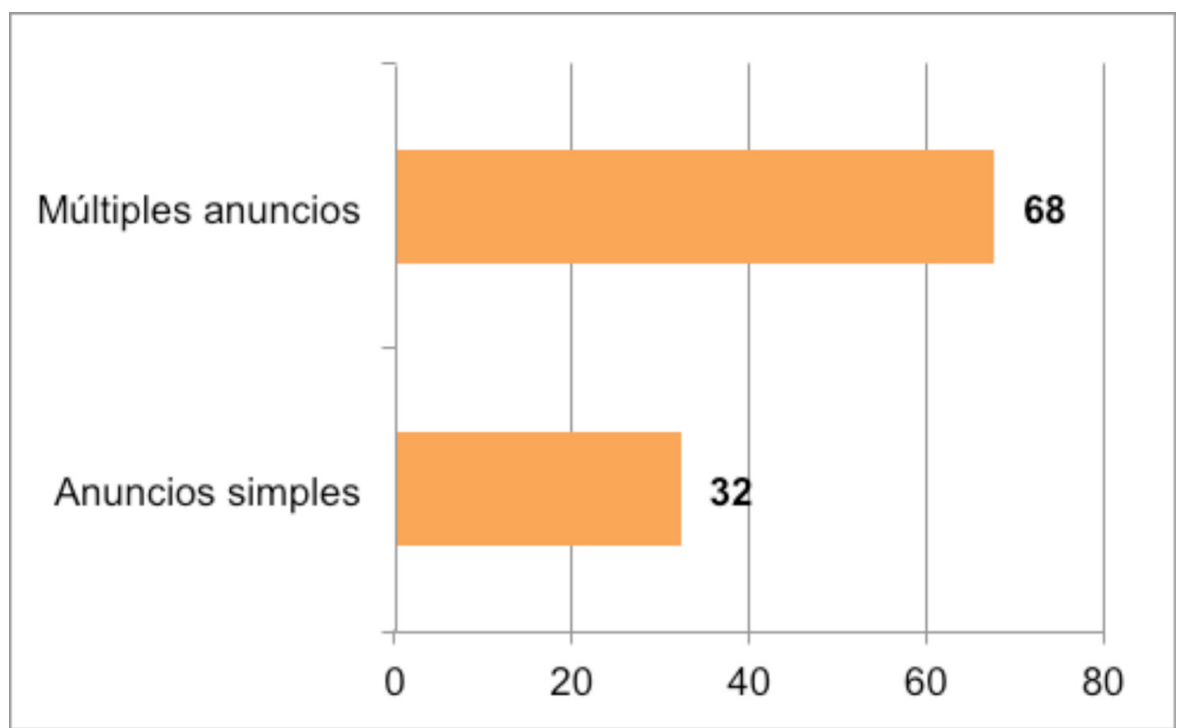

del alquiler de las viviendas. De todas maneras, los números de Inside Airbnb posibilitan tener una idea de la magnitud del impacto del fenómeno en las zonas residenciales. La plataforma llama la atención sobre los anfitriones con anuncios múltiples, señalando que es poco creíble que vivan en la misma propiedad que alquilan, lo cual supone una violación de la legislación.

En el listado de anfitriones con más anuncios, elaborado por Inside Airbnb y que se reproduce en la Figura 5, se observa las que serían denominaciones de empresas. En total son 4 de los 20 mayores anunciantes. Uno de ellos, Home at Homes, tenía 46 anuncios. Con mucha probabili-
Figura 4: Tipos de anuncios de viviendas con fines turísticos de la ciudad de Sevilla en la plataforma de Airbnb. En porcentaje. Fuente: Inside Airbnb, consultado el 21 de mayo de 2019. Elaboración propia.

Figura 5: Anfitriones de la ciudad de Sevilla con mayor cantidad de anuncios de viviendas turísticas en la plataforma de Airbnb. Setiembre, 2019. Fuente: Inside Airbnb, consultado el 10 de octubre de 2019. Elaboración propia.

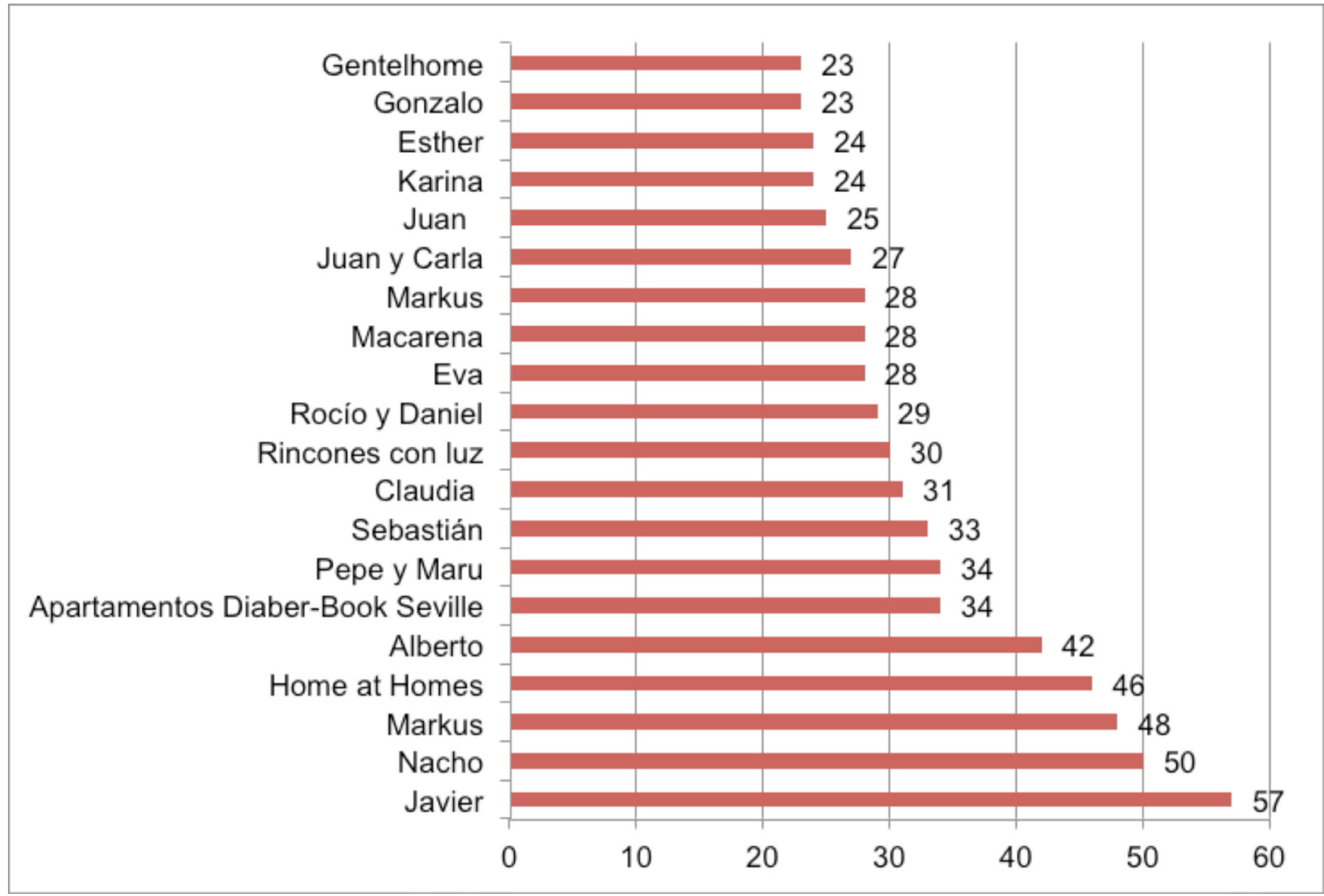


Figura 6: Tipo de habitaciones de la ciudad de Sevilla ofertadas en la plataforma de Airbnb. Setiembre, 2019. En porcentaje. Fuente: Inside Airbnb, consultado el 10 de octubre de 2019. Elaboración propia.
Figura 7: Frecuencia de disponibilidad de viviendas con fines turísticos de la ciudad de Sevilla según anuncios en la plataforma de Airbnb. Setiembre, 2019. En porcentaje. Fuente: Inside Airbnb, consultado el 10 de octubre de 2019. Elaboración propia. dad no serían particulares tal como es la intención señalada por Airbnb. En los otros casos, pese a que los anfitriones se encuentran identificados con nombres de personas, la alta cantidad de anuncios realizados por cada uno de ellos, como señala el portal Inside Airbnb, hace suponer que se tratarían en realidad de empresas o propietarios de muchos pisos.

Si bien es cierto que hay familias que han encontrado en esto una forma de tener un ingreso extra, una manera de salvar la situación de desempleo, etc., es necesario que una familia tenga una vivienda que le sobre. Quiere decir que por lo menos tiene que tener una vivienda para compartir, que de hecho no es lo mayoritario, entonces deben ser dos viviendas [...]. O sea, tiene que ser una clase media que pueda ser propietaria o casi propietaria de una vivienda, o de dos, para poner una en alquiler turístico (L. Berranquero, comunicación personal, 26 de julio de 2018).

En toda la ciudad de Sevilla, según se muestra en la Figura 6, el 81\% de las ofertas anunciadas en Airbnb correspondían a casas o apartamentos enteros, a setiembre de 2019; el 18\% eran habitaciones privadas y solo el $0,3 \%$, o sea 14 anuncios, eran habitaciones compartidas.

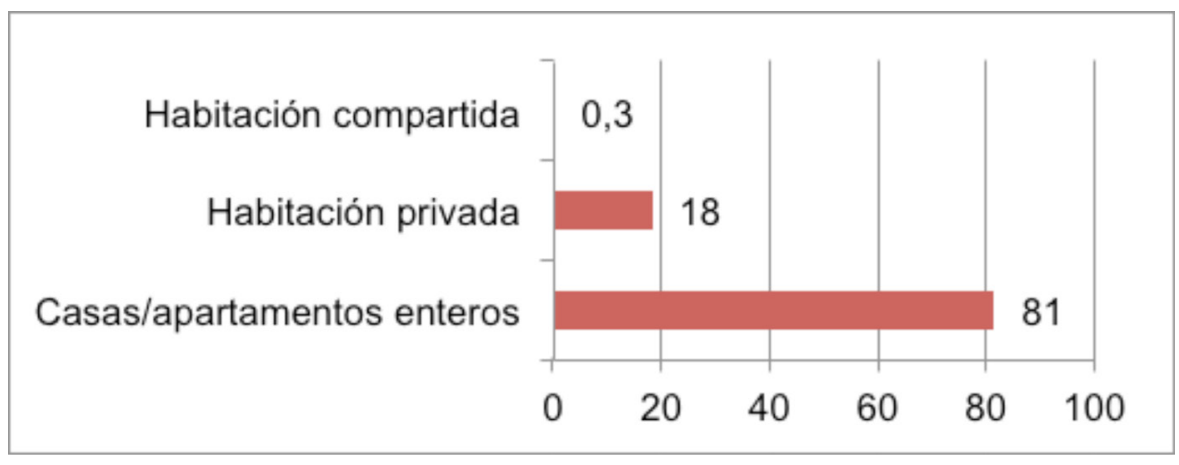

Solo en el caso de habitaciones privadas o compartidas podría hablarse de un ingreso extra para parte de la población local.

Ese es uno de los mitos. Es cierto que estas plataformas permiten poner una vivienda en alquiler. De hecho, uno de los slogans que tiene Airbnb es que los turistas pueden entrar a convivir con personas locales y eso no es así. La mayor parte de los apartamentos que se ofertan en Airbnb no son apartamentos compartidos con las personas que viven allí (L. Berranquero, comunicación personal, 26 de julio de 2018).

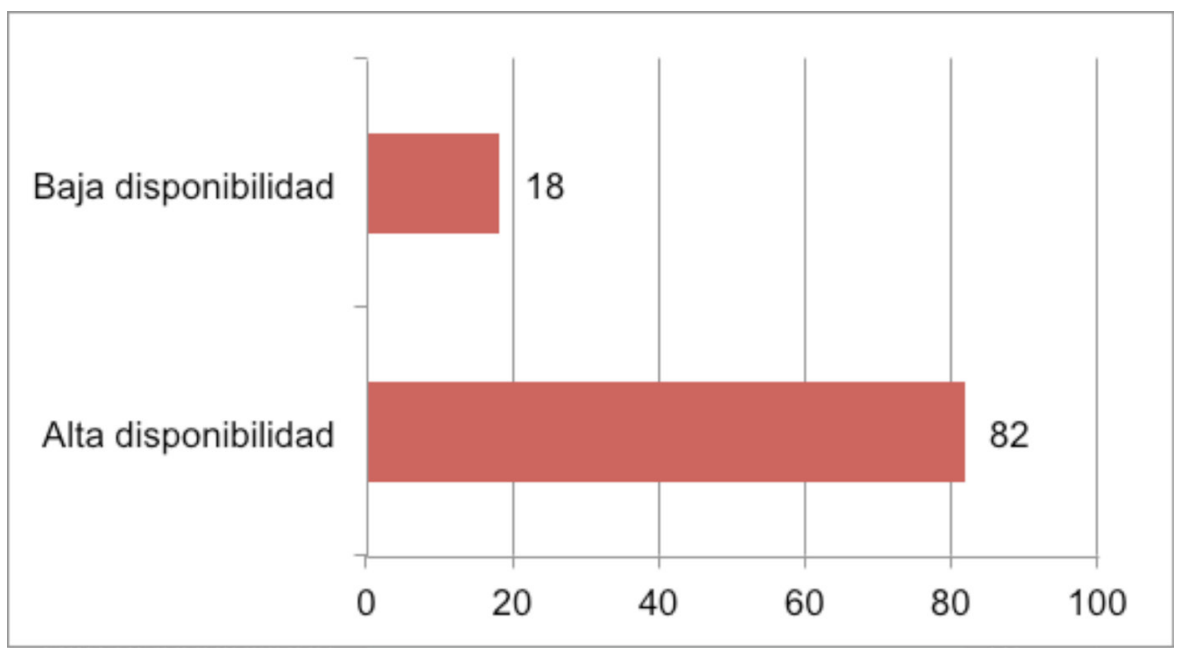


Otro aspecto que refuerza lo anterior es el anuncio de la alta disponibilidad durante el año de las viviendas con fines turísticos en la plataforma de Airbnb, lo cual estaría confirmando que los propietarios de esas casas o apartamentos no viven en el lugar, por lo tanto, los anfitriones pertenecen a clases acomodadas que cuentan con varias viviendas $o$ son directamente empresas o gestores de alquiler turístico. La Figura 7 muestra que el $82 \%$ de las viviendas se encontraban altamente disponibles para el alquiler. Esto pone en entredicho la idea de generación de ingresos adicionales para los habitantes de una ciudad compartiendo un espacio de su residencia con los turistas, tal como lo plantea Airbnb.

\section{Evolución del costo del alquiler y precios de viviendas sevillanas}

Desde octubre del año 2014 al mes de agosto del 2019, el precio del alquiler en Sevilla ha registrado un incremento del 32\%, pasando de 7,6 a 10 euros el metro cuadrado como muestra la Figura 8.

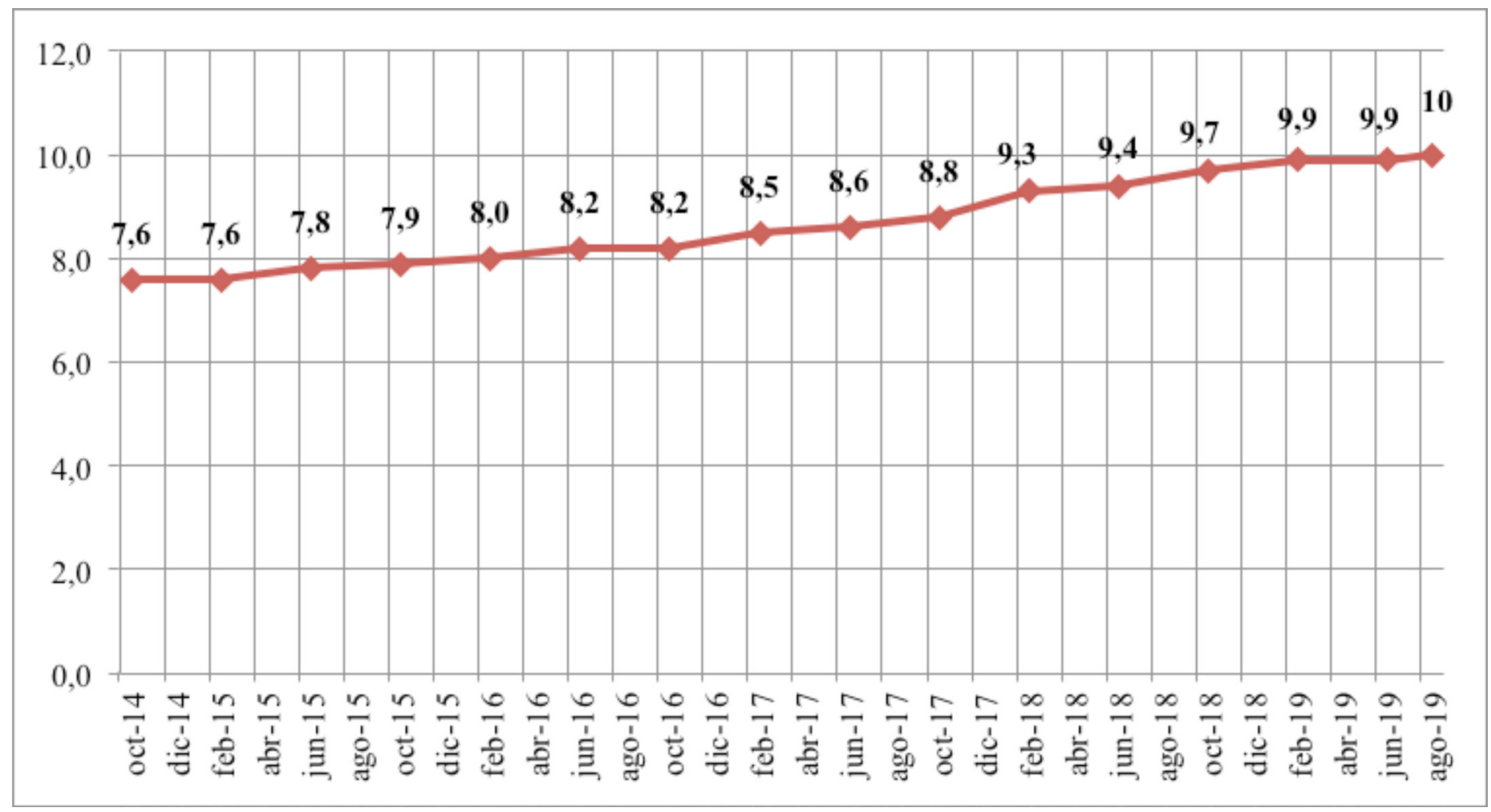

$\mathrm{Al}$ observar el comportamiento de los precios de los alquileres en los 4 distritos de Sevilla con mayor cantidad de viviendas con fines turísticos se puede constatar un comportamiento similar. En Macarena se produjo el mayor aumento en el período comprendido entre octubre del año 2014 al mes de agosto de 2019, de 6,6 a 8,8 euros el metro cuadrado, un incremento del $35,4 \%$, mayor a la media sevillana en términos relativos de aumento (Figura 9). A pesar de ello registra el precio más accesible de alquiler con relación a los otros distritos con mayor cantidad de viviendas con fines turísticos.

En el Casco Antiguo, donde los precios de los alquileres son los más altos, se constata en el mismo período una suba desde 8,7 a 11,5 euros el metro cuadrado, un $32,2 \%$. En Triana, el segundo distrito con precios más elevados de alquiler luego del Casco Antiguo, se produjo un salto de 8,1 a 10,7 euros el metro cuadrado, una suba del 32,1\%. Mien-
Figura 8: Costo del alquiler en la ciudad de Sevilla, años 2014-2019. Fuente: Portal inmobiliario Idealista, consultado el 05 de setiembre de 2019. Elaboración propia. 
Figura 9: Aumento de precios de alquiler por distritos con mayor cantidad de viviendas con fines turísticos. Octubre, 2014 - agosto, 2019. En porcentaje. Fuente: Portal inmobiliario Idealista, consultado el 05 de setiembre de 2019. Elaboración propia.

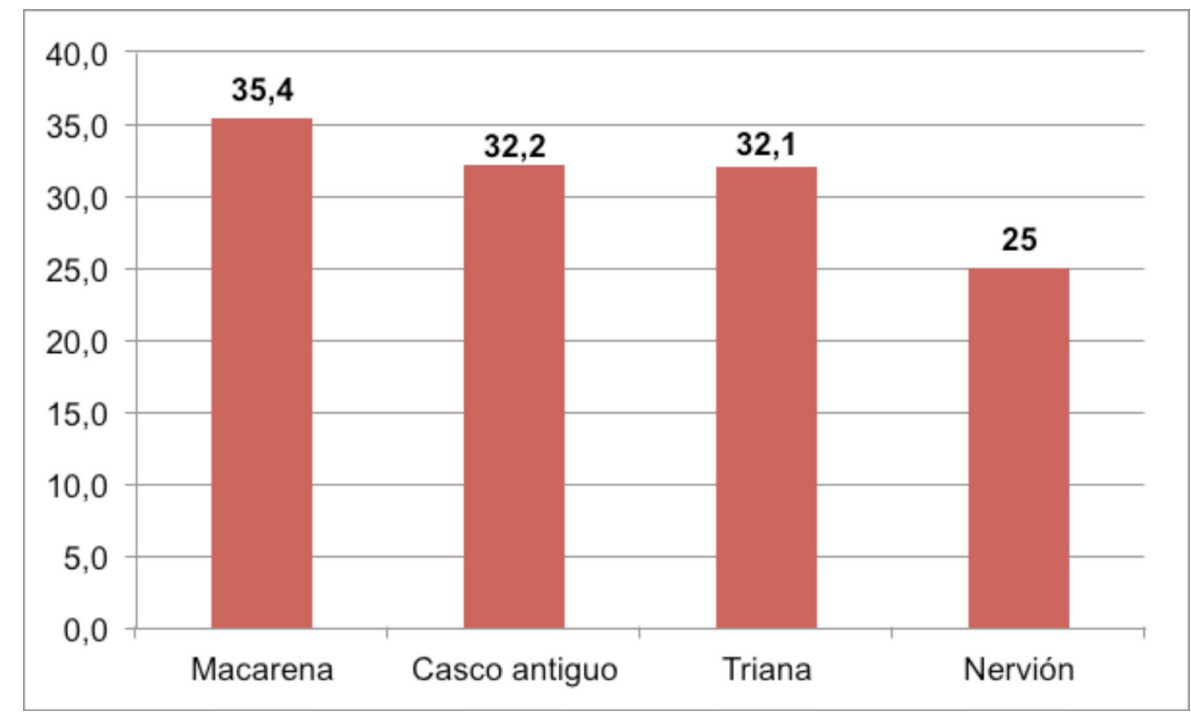

tras tanto en Nervión el alquiler pasó de 8 a 10 euros el metro cuadrado, equivalente a un $25 \%$ de aumento (Figura 9).

En Sevilla el precio por metro cuadrado de una casa ha aumentado en más de 300 euros en 5 años, lo que equivale a un $18 \%$ de suba (Figura 10).

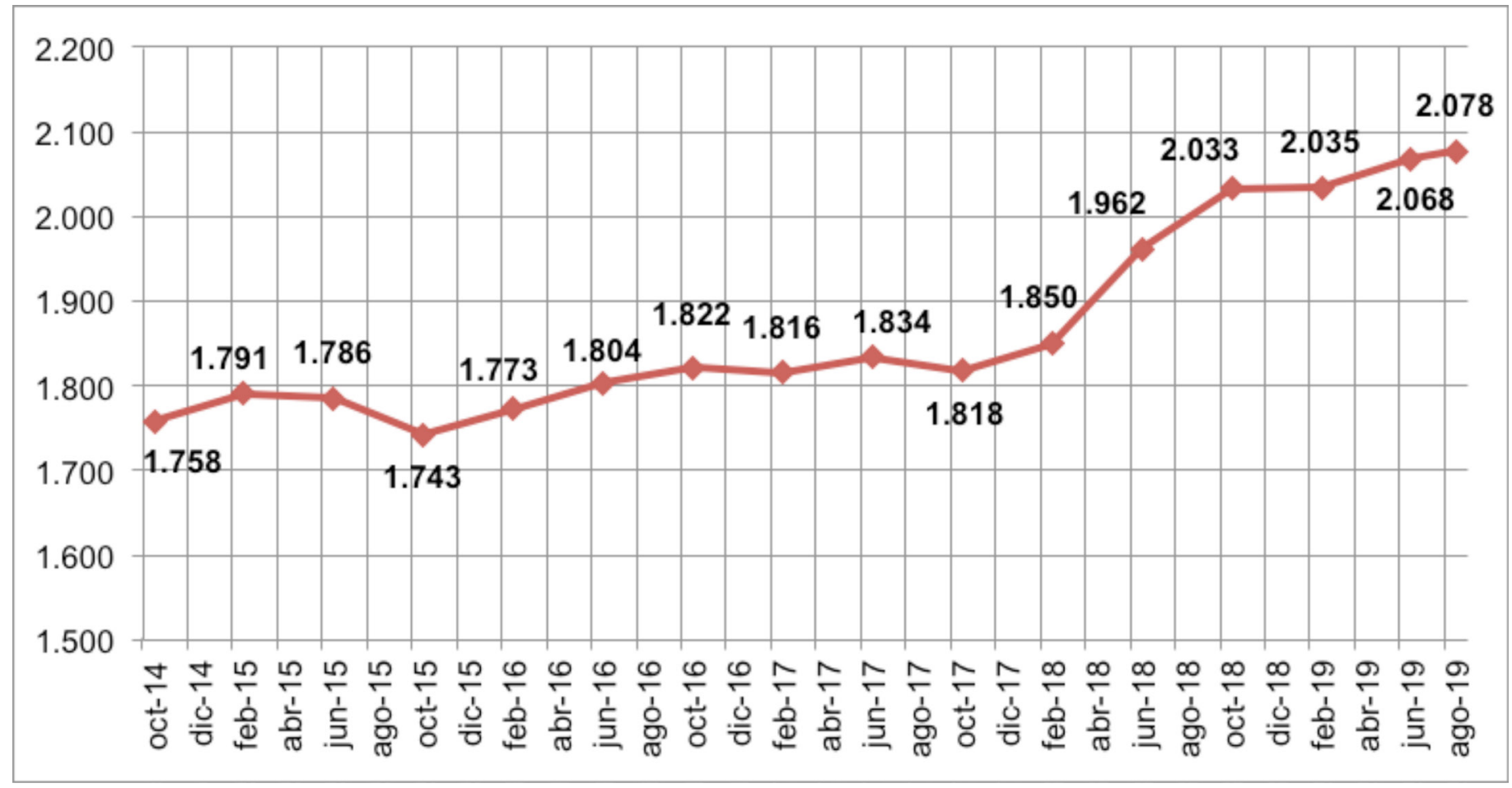

Figura 10: Evolución del precio de la vivienda en la ciudad de Sevilla. En euros por metro cuadrado Años 2014-2019. Fuente: Portal inmobiliario Idealista, consultado el 05 de setiembre de 2019. Elaboración propia.
En el Casco Antiguo, Triana y Nervión, los 3 distritos con mayor cantidad de viviendas con fines turísticos, el incremento del precio por metro cuadrado de las casas ha superado a la suba registrada en toda la ciudad. Entre octubre del 2014 y agosto de 2019, el precio de una vivienda en el Caso Antiguo pasó de 2370 a 2989 euros, 610 euros más. En Triana saltó de 1951 a 2546 euros, casi 600 euros más por metro cuadrado. Mientras tanto en Nervión pasó de 2108 a 2498 euros, aproximadamente 400 euros el metro cuadrado en el mismo período. En términos relativos fue Triana el distrito con mayor porcentaje de aumento registrado con un incremento del 30,5\%. En segundo lugar, se ubicó el 
Casco Antiguo, donde se verifican los precios más altos de Sevilla, con un $26,1 \%$. El tercer lugar corresponde a Nervión con aproximadamente un $20 \%$ de aumento (Figura 11).

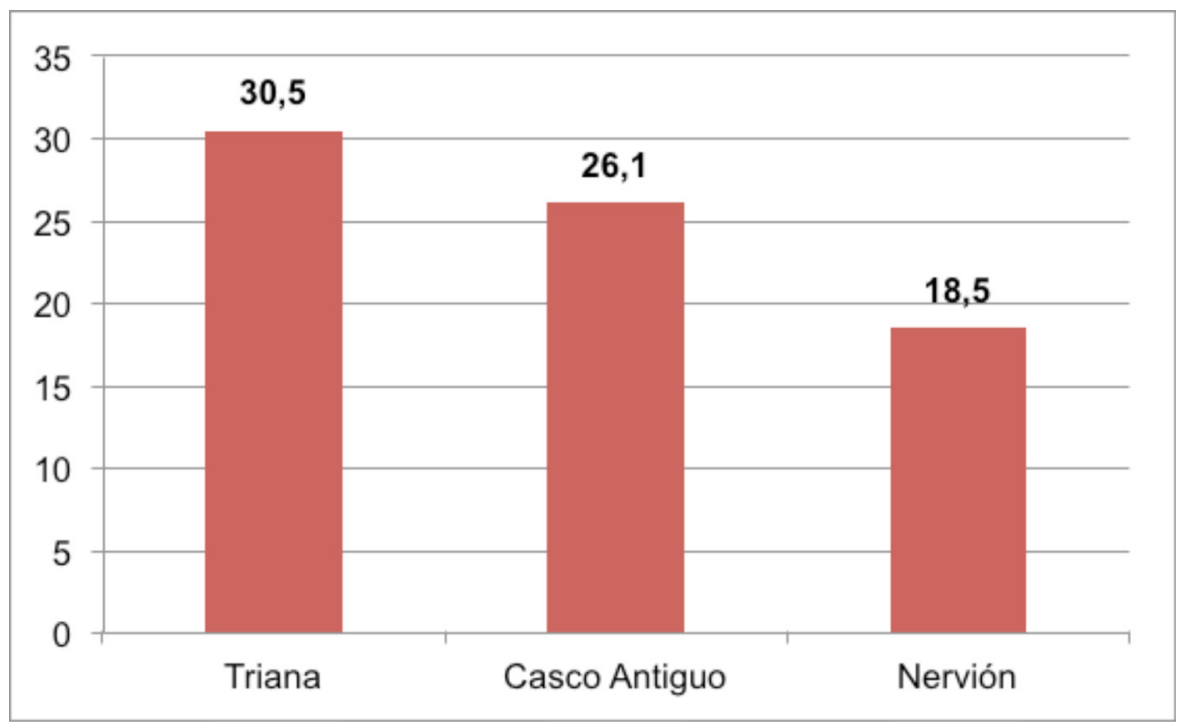

\section{Efectos de la turistización experimentados por los} residentes sevillanos

El incremento de la oferta de viviendas para hospedaje turístico ha sido considerado en los últimos años la causa de la expulsión de los inquilinos de la ciudad de Sevilla.

Hay un fenómeno de desplazamiento [...] hay casos de desahucio, es decir, de gente que no puede pagar el alquiler de una vivienda y entonces es expulsada. Lo siguiente que ocurre en esa vivienda es que pasa a ser de uso turístico. Hay otros casos de gente que sí paga su alquiler regularmente, un inquilino normal, que no tiene problemas, pero se le acaba el contrato y el propietario en lugar de renovarlo decide no seguir porque va destinar la vivienda para uso turístico (J. Jover, comunicación personal, 23 de julio de 2018).

Para el sector popular sevillano se ha vuelto prohibitivo vivir en determinados lugares de la capital de la comunidad autónoma de Andalucía, como señala Lola Giménez, actriz de teatro, cine y televisión, comprometida con las causas populares sevillanas.

A las clases populares, sobre todo, no les están dando la oportunidad de vivir en la zona que quieren, las están desplazando al extrarradio [...]. $\mathrm{Y}$ eso es muy doloroso porque no nos permite a los ciudadanos vivir donde queremos [...] los precios suben, los alquileres se vuelven insostenibles. Por supuesto no puedes comprar nada ahí salvo que tengas muchísimo dinero y la gente del pueblo tenemos un sueldo, y nosotros que somos artistas, la mitad de las veces ni ese sueldo (L. Giménez, comunicación personal, 1 de agosto de 2018).

Tal vez estemos asistiendo a un estadio de endurecimiento de la lógica expulsora de los sectores populares en las áreas en las que tienen lugar importantes procesos de acumulación capitalista. Según Víctor Fernández Salinas (2003), a lo largo del siglo xx en las distintas fases
Figura 11: Aumento de precios de casas por distritos con mayor cantidad de viviendas con fines turísticos. Octubre, 2014 - agosto, 2019. En porcentaje. Fuente: Portal inmobiliario Idealista, consultado el 05 de setiembre de 2019. Elaboración propia. 
de la expansión urbana de Sevilla se han adoptado estrategias y se han puesto en funcionamiento instrumentos y mecanismos para transformar el espacio de la ciudad, especialmente el área histórica, localizada en el centro sevillano, en aquello apetecido por las clases dominantes, asignándole a la zona nuevos roles que le permitieran competir mejor en el mercado global, potenciando algunos aspectos y dejando al margen de la "ciudad oficial" aquellos considerados irrelevantes desde el punto de vista económico, tales como las poblaciones pertenecientes a la clase proletaria que fueron desplazándose a lo largo de los años de los inmuebles en los que residían, conocidos como corrales de vecinos.

El corral de vecinos es una tipología que viene de la tradición de la vivienda árabe, la fachada es normalmente muy austera. Tiene una entrada y se estructura a través de un patio central donde dan todos los departamentos que además normalmente son de una pequeña habitación o de dos. Los vecinos compartían todo, el baño, cocina y eso creaba un sentimiento de comunidad. Esa tipología, patio de vecinos en Triana había muchísimo y se ha perdido casi todo (J. Jover, comunicación personal, 23 de julio de 2018).

La desaparición de los corrales de vecinos o casas de vecindad implica también, como lo indica Fernández Salinas (2003), la desaparición de un espacio en el que era posible la transmisión de los valores ligados a la solidaridad. Uno de los efectos del desplazamiento de la población de los barrios por la turistización es la eliminación de la capacidad de organización de los vecinos, desestructurando las redes de solidaridad que fueron propias de la vecindad y, por, sobre todo, tal como lo señala Ana Jiménez, integrante del Colectivo Asamblea contra la Turistización de Sevilla (CACTUS), vacía de contenido a la ciudad.

Todo el tejido social desaparece, o sea, lo que están haciendo allí es robándole el alma a la ciudad [...], o sea, toda la estructura social, todo el arraigo del barrio, toda la cultura, todo, los pocos trabajos artesanales que quedan, todo eso va desapareciendo poco a poco [...]. La van vaciando, se está transformando en un escaparate, un escaparate para el turismo, para el negocio, una ciudad mercancía (A. Jiménez, comunicación personal, 2 de agosto de 2018).

Un interesante diagnóstico realizado por alumnos y alumnas del sexto año de la educación primaria de una institución educativa de la ciudad de Sevilla, Huerta de Santa Marina, en el marco de la ejecución del proyecto "Participar para poner la vida en el centro", durante el 2017 y 2018, puso de manifiesto, desde la perspectiva infantil, los principales problemas causados por el proceso de turistización (Figura 12). La suba de precios de la vivienda, de los bienes y servicios básicos, la modificación del entorno y las costumbres, la generación de alta cantidad de basura, fueron algunas de las situaciones identificadas en el proceso por los niños y niñas, para quienes la problemática afecta principalmente a las personas de menos recursos económicos.

Como consecuencia del impacto generado por el turismo intensivo en la ciudad de Sevilla, se llevó a cabo en noviembre del 2017 en la capital de Andalucía el primer Encuentro sobre Turistización, Resistencias y Alternativas (ENTRA), espacio en el que se analizaron los problemas generados por el proceso, de manera especial la expulsión de los inquilinos de un importante número de pisos cuyos arrendadores 
decidieron destinarlos para alojamiento turístico. El encuentro dio nacimiento al Colectivo Asamblea contra la Turistización de Sevilla (CACTUS), cuya juventud es un indicador de la irrupción agresiva del fenómeno de manera reciente en la ciudad.

El año pasado [2017] se organizó, impulsado por la "Asociación de vecinas y vecinos en la revuelta", y por otras personas y otros colectivos, un encuentro que se llamaba ENTRA, que era Encuentro de Turistización y Resistencia y Alternativa”, donde nos encontramos diferentes personas y colectivos de la ciudad de Sevilla y otras partes del Estado y fuera del Estado, gente de Portugal vino también, de las islas, de Cataluña, de Madrid y otras partes de Andalucía también (A. Jiménez, comunicación personal, 2 de agosto de 2018).

CACTUS ha combinado desde su nacimiento asambleas presenciales y discusiones virtuales (Fernández-García, Hernández Conde y Barragán Robles, 2019). Algunas de las actividades del Primer Encuentro sobre Turistización, Resistencias y Alternativas (ENTRA) se llevaron a cabo en la conocida Casa-Palacio del Pumarejo. El inmueble, uno de los pocos en los que persiste el modo de vida de un corral de vecinos y que se constituye en un vestigio de la antigua organización comunitaria vecinal sevillana caracterizada por sus redes de apoyo mutuo, fue defendido pocas décadas atrás con firmeza por los vecinos ante los intentos de transformarlo en un establecimiento de alojamiento turístico, tal como relata uno de los propulsores del centro vecinal que funciona en el lugar, Paco Aragón.

Hace 20 años esto lo compró un hotel. Cuando los vecinos se enteraron que querían construir un hotel, esto está catalogado como Bien de Interés Cultural $[\ldots]$. Entonces los vecinos lo que hicieron fue..., un montón de vecinos aquí, tomarlo [...]. Entonces eso fue hace más o menos 20 años y bueno, cuando los vecinos se atrincheraron aquí...siguieron viviendo los vecinos. Cogimos los usos que son ahora la asamblea, hay varios usos, oficinas $[\ldots]$ oficinas para migrantes, bibliotecas y cogimos los usos...y empezamos una batalla para que no hicieran el hotel, que esto siguiera [...]. Entonces fuimos nosotros los vecinos, el movimiento vecinal, quien realmente esto lo ha mantenido [...]. Y aquí nos piden el espacio muchas asociaciones, muchos colectivos, y nosotros en funciones de que si se está libre pues se lo damos, a todos los organizados (P. Aragón, comunicación personal, 1 de agosto de 2018).

En la Casa-Palacio del Pumarejo, los residentes de la ciudad o los migrantes encuentran una mano amiga.

Y acá también hay una asociación de mujeres supervivientes que lo lleva una amiga nuestra, Antonia Ávalos, mexicana, y bueno atiende a todas las mujeres, un comedor social donde vienen a comer, no se paga nada, y bueno acogen, orientan, asesoran a las mujeres maltratadas que vienen de conflictos bélicos de países donde la violencia hacia la mujer es aún mayor que aquí en Europa [...]. Y quien se acerca come, siempre hay un plato de comida de forma gratuita (L. Giménez, comunicación personal, 1 de agosto de 2018).

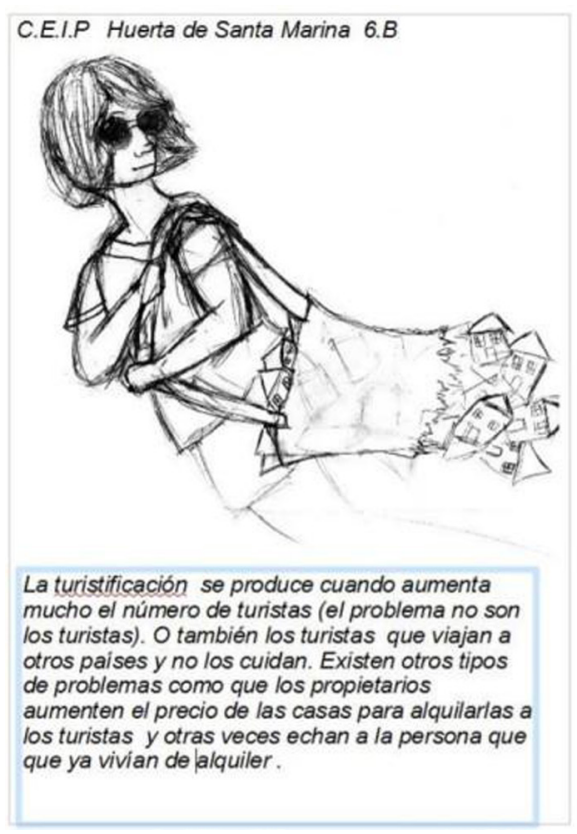

Figura 12: Impactos del turismo intensivo en Sevilla desde la perspectiva infantil. Fuente: Memoria final del Proyecto "Participar para poner la vida en el centro", p. 10. 
Figura 13: Residente de la Casa del Pumarejo charlando desde la ventana con vecinos que se encuentran en el patio del corral. Fuente: Fotografía propia, 01 de agosto de 2018
Figura 14: Campaña de sensibilización sobre el impacto del turismo intensivo en la vivienda, a cargo de alumnos y alumnas del CEIP Huerta de Santa Marina, ciudad de Sevilla. Fuente: Memoria final del Proyecto "Participar para poner la vida en el centro", p. 13.

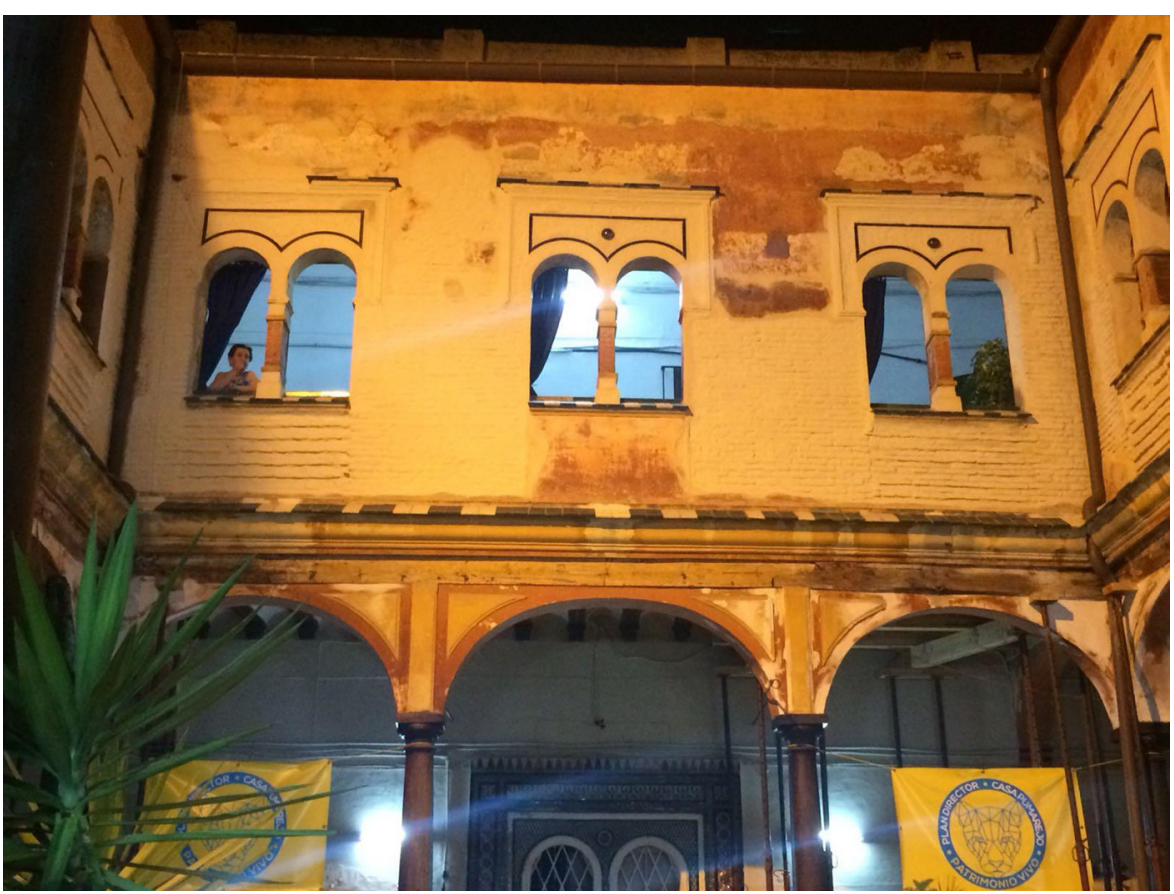

Para informar a la opinión pública sobre el impacto del turismo en su ciudad, alumnos y alumnas de la educación primaria de Sevilla elaboraron varios materiales que se constituyen en la base de una campaña de contra-publicidad. Los estudiantes recalcan en la difusión que realizan que no están en contra del turismo sino en contra de los impactos negativos de la turistización, los cuales describen gráficamente.

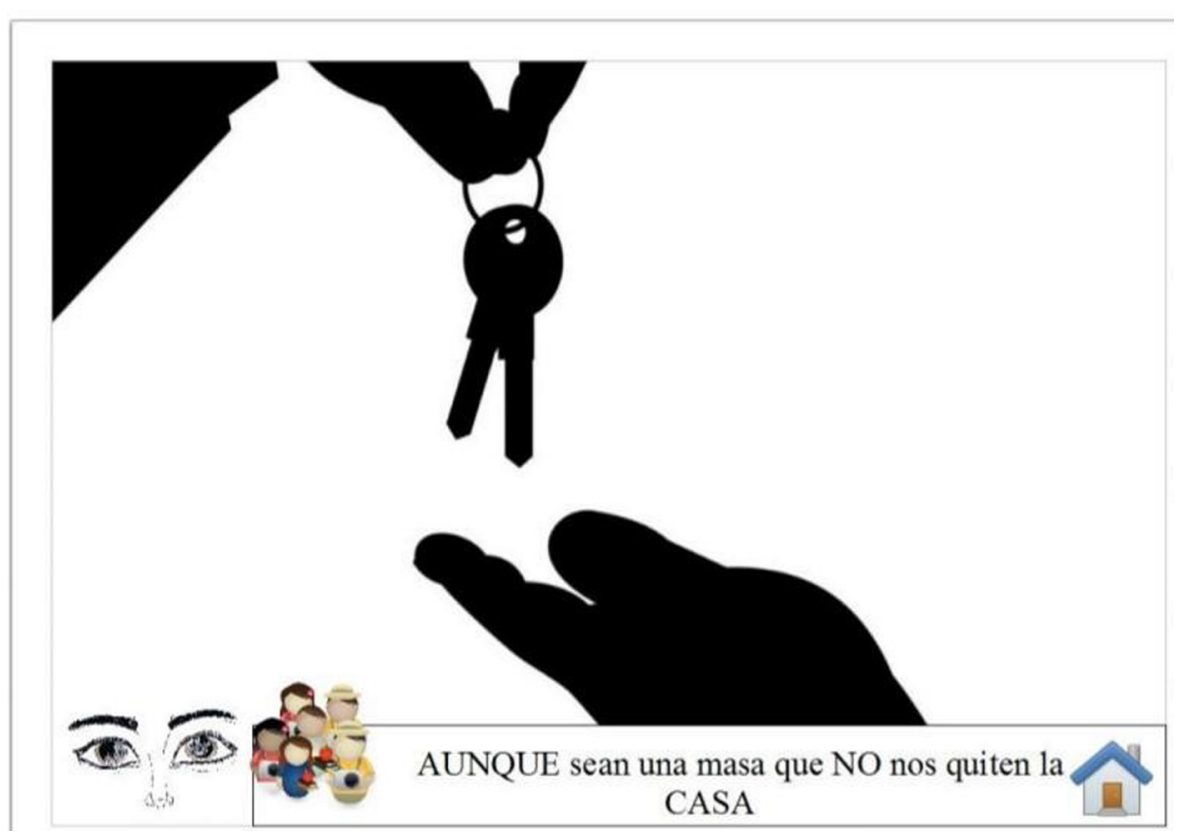

\section{Conclusiones}

La irrupción de las plataformas virtuales fue determinante en la aparición del servicio de viviendas con fines turísticos, posibilitando la conexión entre arrendadores de pisos con potenciales clientes de todo el mundo, una creciente llegada de excursionistas a las ciudades y, por ende, la configuración de la gentrificación turística (Gotham, 2005). En Sevilla, las viviendas turísticas se convirtieron en una de las principa- 
les categorías de alojamiento, lo que se hizo visible a partir del registro obligatorio que estableció en 2016 por decreto la Junta de Andalucía.

Los alquileres de larga duración destinados al uso residencial fueron migrando al mercado de arrendamiento exclusivo para turistas, lo que produjo como resultado la cancelación de los contratos con los inquilinos, quienes no tuvieron otra opción que abandonar sus barrios ante la tajante decisión de los arrendadores, los que, en otros casos, para conseguir el mismo objetivo, la expulsión de los residentes, elevaron de manera importante los precios del alquiler.

En efecto, el precio del alquiler se ha incrementado en un $32 \%$ en la ciudad de Sevilla entre el 2014 y el 2019, en especial en los cuatro distritos con mayor concentración de ese tipo de alojamientos: el Casco Antiguo, Triana, Nervión y Macarena. Todo esto ha influido también sobre los precios de las viviendas sevillanas, los que igualmente son más altos en las áreas con mayor concentración de ofertas de pisos turísticos. El precio de las viviendas sevillanas saltó en 300 euros por cada metro cuadrado entre los años 2014 y 2019, llegando a más de 600 euros en el centro de la ciudad, mayor al doble del promedio registrado en Sevilla.

La resistencia organizada contra el impacto del turismo intensivo en Sevilla es reciente. El Colectivo Asamblea contra la Turistización de Sevilla (CACTUS) empezó a dar sus primeros pasos tras el Primer Encuentro sobre Turistización, Resistencias y Alternativas (ENTRA), llevado a cabo en noviembre del 2017. Sus integrantes consideran que la migración del alquiler residencial al de tipo turístico no solo expulsa a la población residente, sustituida por un movimiento incesante de turistas que se hospedan en los pisos, sino que con el vaciamiento de los barrios desaparecen también las redes de solidaridad que han sido propias de las vecindades sevillanas, lo que además debilita notablemente o anula el activismo social. Estos dos últimos aspectos son quizá los mayores impactos del turismo intensivo. Los testimonios de ciudadanos y ciudadanas de Sevilla, recogidos en el 2018, señalaban que si eventualmente estallara la burbuja de alquileres turísticos y existieran condiciones para retornar a las áreas que hoy desplazan a la población, lo que tal vez no podría recomponerse son esas redes de relacionamiento y ayuda mutua que existían en la vecindad. 


\section{Referencias bibliográficas}

Ayuntamiento de Sevilla (2015). Anuario estadístico de la ciudad de Sevilla, 2015. Sevilla. Recuperado el 19 de setiembre de 2018 de: http:/ /www.sevilla.org/ documentos/estadistica/AnuarioEstadistico2015. pdf.

Ayuntamiento de Sevilla (2016). Anuario estadístico de la ciudad de Sevilla, 2016. Sevilla. Recuperado el 19 de setiembre de 2018 de: https:/ / www.sevilla.org/ servicios/servicio-de-estadistica-empadronamiento/ datos-estadisticos/anuarios/2016.

Barata-Salgueiro, Teresa (2017). Alojamentos Turísticos em Lisboa. Scripta Nova, 21(578). DOI: https:/ / doi.org/10.1344/sn2017.21.18587.

Barrero Rescalvo, María y Jover Baéz, Jaime (2021). Paisajes de la turistificación: una aproximación metodológica a través del caso de Sevilla. Cuadernos geográficos, 60(1), 13-34. DOI: http://dx.doi. org/10.30827/cuadgeo.v60i1.13599.

Benach Rovira, Nuria (2016). ¿Ciudades en el mapa o en la guía turística? Venta de la ciudad y sentido del lugar. Revista CIDOB d'Afers Internacionals, 113, 89-105. DOI: https://doi.org/10.24241/ rcai.2016.113.2.89.

Berraquero Díaz, Luis (2016, 11 de abril). Tres caras de la Sevilla neoliberalizada. El topo, \#15. Recuperado el 24 de julio de 2018 de: http:/ / eltopo.org/ tres-caras-de-la-sevilla-neoliberalizada/.

Blázquez Salom, Macià y Murray Mas, Ivan (2010). Una geohistoria de la turistización de las islas Baleares. El Periplo Sustentable, 18, 69-118.

Cabrerizo, Casilda, Sequera, Jorge y Bachiller, Pablo G. (2016, 9 de enero). Entre la turistificación y los espacios de resistencia en el centro de Madrid: Algunas claves para (re) pensar la ciudad turística. Ecología política, 52. Recuperado el 2 de junio de 2018 de: https: / / www.ecologiapolitica.info/?p=6775.

CACTUS [en línea]. Recuperado el 24 de julio de 2018 de: https:/ / cactusevilla.wordpress.com/.

Centro de Datos Turísticos (2018). Informe anual 2017. Sevilla: Consorcio de turismo de Sevilla. Recuperado el 17 de setiembre de 2018 de: http:/ / www.visitasevilla.es/sites/default/files/professionals / files/ Informe \% 20anual \% 202017.pdf.

Consejería de Turismo y Deporte de la Junta de Andalucía [en línea]. Recuperado el 15 de setiembre de 2018 de: http:/ / www.juntadeandalucia.es/turismoydeporte/opencms/estadisticas-consejeria/.

DataHippo [en línea]. Recuperado el 20 de mayo de 2019 de: https://datahippo.org/es/.

Decreto 28/2016, de las viviendas con fines turísticos y de modificación del Decreto 194/2010, de 20 de abril, de establecimientos de apartamentos turísti- cos. Boletín Oficial de la Junta de Andalucía, del 11 de febrero de 2016. Recuperado el de de 24 julio de 2021 de: https:/ / www.juntadeandalucia.es / boja/2016/28/6.

Díaz Orueta, Fernando y Lourés Seoane, $M^{\mathrm{a}}$ Luisa (2013). Neoliberalismo, políticas urbanas y reconfiguración socio-espacial. Quid 16(3), 7-16.

Díaz Parra, Ibán (2011). Segregación, Intervención Urbanistica y Cambio Social en Sevilla. La Gentrificación del Sector San Luis-Alameda en el Marco del Planeamiento General de 1987 (Tesis doctoral). Departamento de Geografía Humana, Universidad de Sevilla, Sevilla.

Díaz Parra, Ibán y Jover, Jaime (2021) Overtourism, place alienation and the right to the city: insights from the historic centre of Seville, Spain. Journal of Sustainable Tourism, 29(2-3), 158-175. DOI: https:// doi.org/10.1080/09669582.2020.1717504.

Ecotono (2018). Memoria final del Proyecto "Participar para poner la vida en el centro". Sevilla: Agencia Andaluza de Cooperación Internacional para el Desarrollo.

Empresa Pública para la Gestión del Turismo y del Deporte de Andalucía (2016). Oferta turística en Andalucía. Año 2016. Sevilla: Consejería de Deporte y Turismo. Recuperado el 29 de setiembre de 2018 de: http:/ / www.juntadeandalucia.es/turismoydeporte/ publicaciones/estadisticas/oferta_2016_v2.pdf.

Empresa Pública para la Gestión del Turismo y del Deporte de Andalucía (2017). Oferta turística en Andalucía. Año 2017. Sevilla: Consejería de Deporte y Turismo. Recuperado el 29 de setiembre de 2018 de: http:/ / www.juntadeandalucia.es / turismoydeporte/ publicaciones/estadisticas/oferta_2017_v2-1.pdf.

Empresa Pública para la Gestión del Turismo y del Deporte de Andalucía (2018). Oferta turística en Andalucía. Año 2018. Sevilla: Consejería de Turismo, Regeneración, Justicia y Administración Local. Recuperado el 15 de mayo de 2019 de: http:/ / www. juntadeandalucia.es/turismoydeporte/publicaciones/estadisticas/oferta_2018.pdf.

Fernández Salinas, Victor (2003). Vivienda modesta y patrimonio cultural: Los corrales y patios de vecindad en el conjunto histórico de Sevilla. Scripta Nova, 7(146). Recuperado el 30 de octubre de 2018 de: http://www.ub.edu/geocrit/sn/sn-146(070). htm.

Font Garolera, Jaume, Colom Oliva, Mercé y ImbertBouchard Ribera, Daniel (2018). El impuesto turístico de Cataluña. Un primer balance de su aplicación. Scripta Nova, 22(593). DOI: https://doi. org/10.1344/sn2018.22.20220.

Fernández-García, Manuel, Hernández Conde, Macarena y Barragán Robles, Vicente (2019). Rompiendo el consenso: comunidades virtuales y discurso contra-hegemónico en el movimiento contra la turistificación en Sevilla. $I C-$ Revista Científica de Infor- 
mación y Comunicación, 16, 285-323. DOI: https:// dx.doi.org/10.12795/IC.2019.i01.09.

Gerencia de Urbanismo del Ayuntamiento de Sevilla (en línea). Recuperado el 25 de setiembre de 2019 de: https://www.urbanismosevilla.org/.

Gil, Javier y Sequera, Jorge (2018). Expansión de la ciudad turística y nuevas resistencias. El caso de Airbnb en Madrid. Empiria, 41, 15-32. DOI: https:/ / doi.org/10.5944/empiria.41.2018.22602.

Gotham, Kevin F. (2005). Tourism Gentrification: The Case of New Orleans' Vieux Carre (French Quarter). Urban Studies, 42(7), 1099-1121. DOI: https:// doi.org/10.1080/00420980500120881.

Idealista [en línea]. Recuperado el 05 de setiembre de 2019 de: https://www.idealista.com/.

Insideairbnb [en línea]. Consultado el 10 de octubre de 2019 en: http:/ /insideairbnb.com/.

Inzulza-Contardo, Jorge y Díaz Parra, Ibán (2016). Desastres naturales, destrucción creativa y gentrificación: estudio de casos comparados en Sevilla (España), Ciudad de México (México) y Talca (Chile). Revista de Geografía Norte Grande, 64, 109-128.

Instituto de Estadística y Cartografía de Andalucía (en línea). Consultado el 17 de setiembre de 2018 en: https://www.juntadeandalucia.es/institutodeestadisticaycartografia.

Jover Báez, Jaime (2017). Volviendo al centro histórico. La recuperación diferencial del patrimonio y su supeditación a dinámicas urbanisticas. El caso de Sevilla (Tesis doctoral). Departamento de Geografía Humana, Universidad de Sevilla, Sevilla. Recuperado el 2 de junio de 2021 de: https:/ /idus.us.es/handle/11441/63968.

Jover Báez, Jaime (2019). Geografía comercial de los centros históricos: entre la gentrificación y la patrimonialización. El caso de Sevilla. Boletín de la Asociación De Geógrafos Españoles, 82. DOI: https:/ / doi. org/10.21138/bage.2788.

Jover Báez, Jaime, Berranquero, Luis, Barrero, María y Jiménez, Ana (2018). Turistización y movimientos urbanos de resistencia: Experiencias desde Sevilla. En Milano, Claudio y Mansilla, José (Eds.), Ciudad de vacaciones. Conflictos urbanos en espacios turísticos (pp.403-437). Barcelona: Pol-len.

Jover Báez, Jaime y Berraquero Díaz, Luis (2020). ¿Habitantes o visitantes? El impacto del alquiler vacacional en el mercado de vivienda en Sevilla. Ciudad y Territorio. Estudios Territoriales, 52(206), 823-840. DOI: https://doi.org/10.37230/ CyTET.2020.206.07.

Jover, Jaime y Díaz-Parra, Ibán (2019). Gentrification, transnational gentrification and touristification in Seville, Spain. Urban Studies, 57(15), 3044-3059. DOI: https://doi.org/10.1177/0042098019857585.

Milano, Claudio (2018). Overtourism, malestar social y turismofobia. Un debate controvertido. $\mathrm{Pa}$ sos: Revista de Turismo y Patrimonio Cultural, 16(3),
551-564. DOI: https://doi.org/10.25145/j.pasos.2018.16.041.

Murray Mas, Ivan (2014, 9 de julio). Bienvenidos a la fiesta: turistización planetaria y ciudades-espectáculo (y algo más). Ecología política, 47, 87-92. Recuperado el 24 de julio de 2021 de: https:/ / www.ecologiapolitica.info/?p=1661.

Peñarrubia Zaragoza, María Pilar, Simancas Cruz, Moises R., Temes Cordovez, Rafael, Moya Fuero, Alfonso y García Amaya, Alicia (2016). Análisis territorial del alquiler de la vivienda vacacional en las áreas turísticas de litoral de Canarias. En Blázquez Salom, Macià, Mir-Gual, Miquel, Murray Mas, Ivan y Pons Buades, Guillem Xavier (Eds.), Turismo y crisis, turismo colaborativo y ecoturismo. XV Coloquio de Geografía del Turismo, el Ocio y la Recreación de la AGE, (pp. 247-263).

Pereira, Hugo (2018). Urbanismo excluyente versus resistencia en el espacio popular construido en Asunción. Quid 16(9), 91-120.

Richards, Greg (2016). El turismo y la ciudad: ¿hacia nuevos modelos? Revista CIDOB d'Afers Internacionals, 113, 71-87. DOI: https://doi.org/10.24241/ rcai.2016.113.2.71.

Rodríguez, María Carla, Delvalle, Veronica Estela y Ostuni, Fernando Martín (2013). Ciudades neoliberales: políticas urbanas, diseño y justicia social. Quid 16(3), 1-6.

Rodríguez-Antón, José Miguel, Alonso-Almeida, María del Mar, Rubio-Andrada, Luis y Celemín Pedroche, $\mathrm{M}^{\mathrm{a}}$ Soledad (2016). La economía colaborativa. Una aproximación al turismo colaborativo en España. CIRIEC-España, Revista de Economía Pública, Social y Cooperativa, 88, 259-283.

Santucci de Oliveira, Bruno, Eger Bauer, Jonei, Tomelin, Carlos Alberto y Lisboa Sohn, Ana Paula (2019). Economía compartida: Un estudio sobre Airbnb. Estudios y Perspectivas en Turismo, 28(3), 636651.

Villar Lama, Arsenio y Fernández Tabales, Alfonso (2017). Reconstruir la historia del turismo a través de la prensa: la evolución del espacio turístico de Sevilla (1915-2015). Cuadernos Geográficos, 56(1), 290-321. DOI: https://doi.org/10.30827/cuadgeo. v56i1.4714.

Vives-Miró, Sònia y Rullan, Onofre (2017). ¿Desposesión de vivienda por turistización?: Revalorización y desplazamientos en el Centro Histórico de Palma (Mallorca). Revista de geografía Norte Grande, 67, 53-71. DOI: http://dx.doi.org/10.4067/S071834022017000200004.

Yrigoy, Ismael (2017). Airbnb en Menorca: ¿una nueva forma de gentrificación turística? Localización de la vivienda turística, agentes e impactos sobre el alquiler residencial. Scripta Nova, 21(580). DOI: https://doi.org/10.1344/sn2017.21.18573. 
Pereira, Hugo (2021). Migración del uso residencial de la vivienda al alquiler turístico en Sevilla. Impactos en el derecho a vivir en la ciudad. Hábitat y Sociedad, 14, 119-138.

<https://doi.org/10.12795/HabitatySociedad.2021.i14.07>

$\bigcirc$ 